REVIEW PAPER

\title{
CURRENT APPROACHES IN SOURDOUGH PRODUCTION WITH VALUABLE CHARACTERISTICS FOR TECHNOLOGICAL AND FUNCTIONAL APPLICATIONS
}

\author{
BOGDAN PĂCULARU-BURADA*, LUMINIȚA ANCA GEORGESCU, GABRIELA-ELENA \\ BAHRIM \\ *Dunărea de Jos University, 111 Domnească Street, 800201, Galaţi, Romania \\ *corresponding author: bogdan.pacularu@ugal.ro
}

Received on 27 September 2019

Revised on 14 January 2020

\begin{abstract}
The spontaneous fermented cereal-based products are natural ingredients used since ancient times as aroma and texture enhancers or as biopreservatives. Many studies that focus on the sourdough microbiota and its related properties were carried out until now due to the fact that the fermented products with lactic acid bacteria strains have high functionality and support the consumer's decisions in regard to the healthy foods consumption and lifestyle improvement. As such, finding new lactic acid bacteria strains with functional and technological features that could be part of new starter cultures and understanding the biochemical pathways involved in the fermentation process are still the current research objectives for the scientists in this field. This review highlights the newest trends in the sourdough technology by stating the diversity of raw materials and starter beneficial microorganisms in order to obtain functional fermented products, gluten-free sourdoughs, or fermented products rich in postbiotic compounds (i.e. organic acids, bioactive peptides, short-chain fatty acids (SCFA), exopolysaccharides (EPS), enzymes), compounds biosynthesized by the microorganisms that are part of the consortium involved in the fermentation process. Additionally, multiple strategies for the reduction of the antinutritional factors and an increment of the minerals' bioaccessibility are pointed out, as well as the comparisons between the nutritional compounds of some underutilized pseudocereals and grains for the formulation of new sourdoughs that are recommended for the consumers with special nutritional requirements.
\end{abstract}

Keywords: sourdough, beneficial microorganisms, postbiotics, functional ingredients

\section{Introduction}

Traditionally, the sourdough is a cereal-based fermented product with lactic acid bacteria $(\mathrm{LAB})$ and yeasts, which is used as a natural ingredient in the dough

https://doi.org/10.35219/foodtechnology.2020.1.08 
fermentation with valuable technological and functional properties. As a starter culture, the sourdough contains several beneficial microorganisms in the range of $10^{6}-10^{9} \mathrm{CFU} / \mathrm{g}$, which are actively implied in the dough fermentation process, thus impacting the features and stability of baking products and also the consumer's life quality.

In the last years, one major concern for scientists and technologists was the replacement of cereal flours with some pseudocereal flours for the bread and sourdough production technology in order to achieve clean-label and healthy products.

Wheat, triticale, sorghum, oat, rye, chia, barley and maize flours are usually used as fermentation substrates for the sourdough formulation. Nowadays, in the artisanal bakery, the laboratory-scale made sourdoughs are composed by unconventional flours obtained from quinoa, hemp, chickpea, yellow pea, amaranth, teff and buckwheat or rice bran.

The sourdough fermentation can be spontaneously realized by the microorganisms present in the natural wild microbiota of the flours or by selected strains that can be used as starter cultures. The most common LAB and yeast strains associated with the sourdoughs microbiota are presented in Table 1 (Huys et al., 2013).

This review offers a brief overview regarding the actual and modern practices in the sourdough manufacture by emphasizing the fermentation of unconventional flours and their benefits, the microorganisms involved in the fermentation process and their positive implications on the quality, technological and functional properties.

\section{Nutritional benefits of the fermentation substrates}

Composite flours acquired either by a full replacement or a partial substitution of the wheat flour with pseudocereals, cereals, roots, tubers, legumes or by-products are successfully used in the bread making technology due to their capacities to increase the foods' functionality, nutritional value and phytochemical properties. The beneficial microorganisms that were implied in the fermentation of the composite flours made from quinoa, buckwheat and chickpea led to the biosynthesis of postbiotics and parapostbiotics compounds with functional in vivo effects (Rizzello et al., 2015).

The nutrients composition analysis of some unconventional flours (millets, buckwheat, sorghum, maize, rice) compared to wheat flour revealed that the main components are represented by saccharides (average values between $60-81 \mathrm{~g} / 100 \mathrm{~g}$ dry weight) (Taylor, 2017). Furthermore, Little millet and Barnyard millet contain the highest amount of proteins, $15 \mathrm{~g} / 100 \mathrm{~g}$ dry basis, followed by wheat, $12 \mathrm{~g} / 100 \mathrm{~g}$ dry basis, and whole grains sorghum, $11 \mathrm{~g} / 100 \mathrm{~g}$ dry basis. Despite this, Finger millet, Fonio and Japanese barnyard millet can replace wheat and be successfully used as alternative sources of dietary fibers to maximize the positive effects of probiotics in the gut (Duodu and Apea-Bah, 2017). 
Table 1. Lactic acid bacteria and yeasts frequently found in the sourdough's microbiota.

\begin{tabular}{|c|c|c|c|}
\hline \multicolumn{3}{|c|}{ Lactic acid bacteria strains } & \multirow[t]{2}{*}{ Yeast strains } \\
\hline $\begin{array}{l}\text { Obligate } \\
\text { homofermentative }\end{array}$ & $\begin{array}{l}\text { Obligate } \\
\text { heterofermentative }\end{array}$ & $\begin{array}{l}\text { Facultative } \\
\text { heterofermentative }\end{array}$ & \\
\hline $\begin{array}{l}\text { Lactobacillus spp. } \\
\text { (L.acidophilus, } \\
\text { L. amylolyticus, } \\
\text { L. amylovorus, } \\
\text { L. crispatus, } \\
\text { L. delbrueckii ssp. } \\
\text { delbrueckii, } \\
\text { L. farciminis, } \\
\text { L. gallinarum, } \\
\text { L. gasseri, } \\
\text { L. helveticus, } \\
\text { L. johnsonii, } \\
\text { L. mindensis, } \\
\text { L. nagelii, } \\
\text { L. salivarius) } \\
\\
\text { Lactococcus } \\
\text { ssp. lactis } \\
\\
\text { Streptococcus spp. } \\
\text { (S. constellatus, } \\
\text { S. equinus, } \\
\text { S. suis) }\end{array}$ & $\begin{array}{l}\text { Lactobacillus spp. } \\
\text { (L. acidifarinae, } \\
\text { L. brevis, } \\
\text { L. buchneri, } \\
\text { L. cellobiosus, } \\
\text { L. collinoides, } \\
\text { L. crustorum, } \\
\text { L. curvatus, } \\
\text { L. fermentum, } \\
\text { L. fructivorans, } \\
\text { L. frumenti, } \\
\text { L. hammesii, } \\
\text { L. hilgardii, } \\
\text { L. homohiochii, } \\
\text { L. kefiri, } \\
\text { L. kunkeei, } \\
\text { L. lindneri, } \\
\text { L. mucosae, } \\
\text { L. namurensis, } \\
\text { L. nantensis, } \\
\text { L. nodendsis, } \\
\text { L. oris, } \\
\text { L. panis, } \\
\text { L. parabuchneri, } \\
\text { L. pontis, } \\
\text { L. reuteri, } \\
\text { L. rossiae, } \\
\text { L. sanfranciscensis, } \\
\text { L. secaliphilus, } \\
\text { L. siliginis, } \\
\text { L. spicheri, } \\
\text { L. vaginalis, } \\
\text { L. zymae) } \\
\text { Leuconostoc spp. } \\
\text { (Leuc. citreum, } \\
\text { Leuc.gelidum, } \\
\text { Leuc. mesenteroides ssp. } \\
\text { cremoris, } \\
\text { Leuc. mesenteroides ssp. } \\
\text { dextranicum, } \\
\text { Leuc. mesenteroides ssp. } \\
\text { mesenteroides) } \\
\text { Weissella spp. } \\
\text { (W. cibaria, } \\
\text { W. confusa, } \\
\text { W. hellenica, } \\
\text { W. kandleri, } \\
\text { W. paramesenteroides, W. } \\
\text { viridescens) }\end{array}$ & 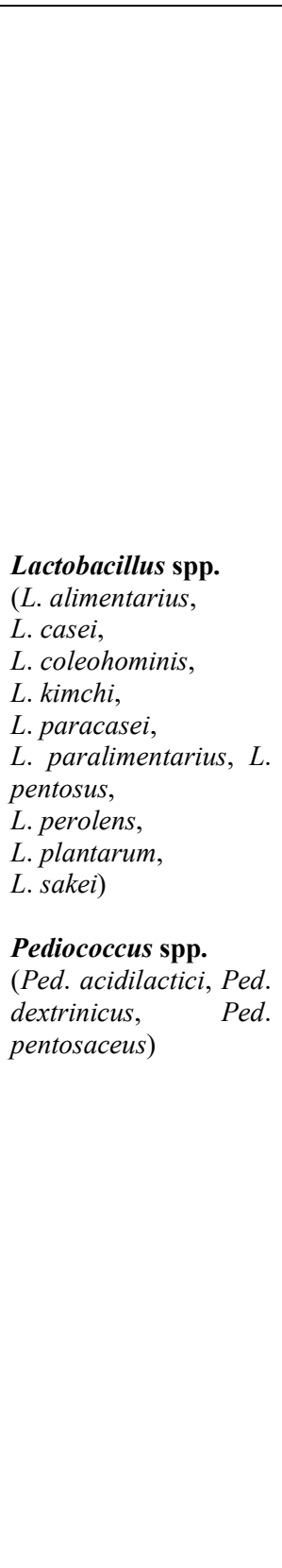 & $\begin{array}{l}\text { Candida } \text { spp. } \\
\text { (C. boidinii, } \\
\text { C. parapsilosis) } \\
\text { Pichia } \text { spp. } \\
\text { (P. ohmeri, } \\
\text { P. guilliermondii, P. } \\
\text { polymorpha, } \\
\text { P. saitoi, } \\
\text { P. stipitis, } \\
\text { P. subpelliculosa) } \\
\text { Yarrowia lipolytica }\end{array}$ \\
\hline
\end{tabular}


Throughout the sorghum whole grains, the most abundant essential amino acid is leucine followed by valine and isoleucine (Awika, 2017). The soybeans incorporation in the sourdough bread modified the levels of the essential amino acids and minerals. The mixture of wheat flour and soybean led to an increment of the lysine content in bread along with an extension of the product's shelf-life. Composite flours made from cereals and legumes (wheat, rye, chickpea, soybean, lentil, beans) are excellent sources of proteins, various essential amino acids, fats and minerals.

The minerals' composition of grains is different, as Table 2 shows, the best source of potassium, phosphorus and calcium is the amaranth (D'Amico and Schoenlechner, 2017).

Table 2. The minerals' content in the sorghum, amaranth and wheat.

\begin{tabular}{lccc}
\hline \multirow{2}{*}{ Mineral content } & \multicolumn{3}{c}{ Average value, mg/100 g grains } \\
\cline { 2 - 4 } & Sorghum & Amaranth & $\begin{array}{c}\text { Hard red } \\
\text { winter wheat }\end{array}$ \\
\hline Iron & 5.7 & 6.41 & 3.19 \\
Zinc & 2.8 & 5.02 & 2.65 \\
Magnesium & 140 & 351.28 & 126 \\
Potassium & 320 & 684.37 & 363 \\
Calcium & 21 & 207.61 & 29 \\
Phosphorus & 337 & 495.57 & 288 \\
\hline
\end{tabular}

For all the analysed samples the iron and zinc concentrations are very low. The bioavailability of minerals depends on the antinutritional factors management and processing technologies.

Even though gliadin and glutenin of rye flour do not form the gluten network, rye is commonly used for bread preparation. Oats are usually used for their proteins and fats, compounds that offer an enhanced nutritional value. The health effects of oats and barley are linked to the soluble and insoluble fibres that can be useful in cholesterol disorders, cardiovascular diseases and inflammatory reactions. Buckwheat seeds have antioxidant, anti-inflammatory, anticarcinogenic and prebiotic properties, which are characterized by the high level of lysine, $B_{1}$ and $B_{2}$ vitamins.

\section{Biotechnological conditions for sourdough production and use}

The scientific literature classifies the sourdoughs into three or four types, depending on the technological processes involved in their production or in the products' state. Type I sourdough is obtained by the spontaneous fermentation of the flour by a wild consortium of LAB and yeasts. It is used in artisanal bakeries after the daily propagation whereas type II sourdough is obtained by flour fermentation with selected LAB strains. Usually, it is available as a liquid starter culture. Type III sourdough is obtained by freeze-drying the type II sourdough and it is used as a leavening agent or as a natural ingredient for flavouring. 
Nonetheless, other related drying techniques can be used. Type IV sourdough is a combination between type I and II sourdoughs (Figure 1).

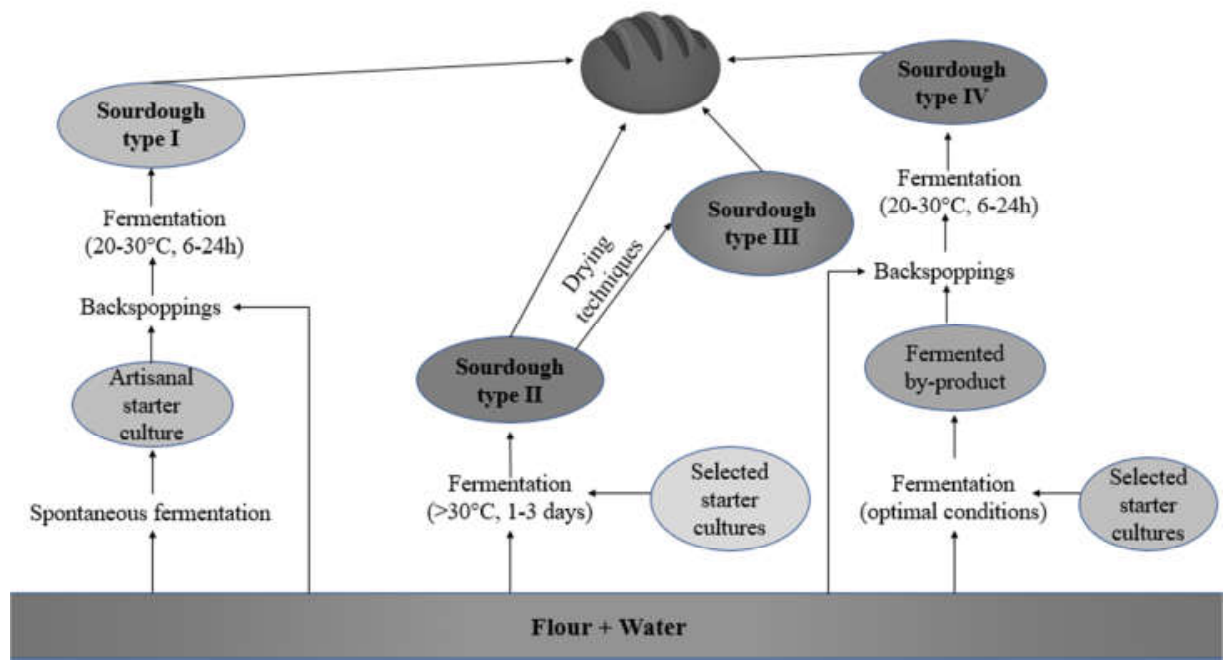

Figure 1. Different types of sourdough production (adapted from Papadimitriou et al., 2019)

The most common LAB strains found in the type I sourdough were Lactobacillus brevis, Lactobacillus alimentarius, Lactobacillus pentosus, Lactobacillus sanfranciscensis, Lactobacillus sakei, Lactobacillus vaccinostercus, Weissella cibaria. Furthermore, Saccharomyces cerevisiae and Candida humilis were the yeast strains that are frequently associated with the type I sourdough microbiota.

The sugars fast and adaptable catabolism by LAB strains belonging to Lactobacillus spp. genera makes them the most dominant species in the sourdough's microbiota. In addition, the sugars metabolism led to the development of antimicrobials, flavour compounds and exopolysaccharides (Papadimitriou et al., 2019). Furthermore, the bacteria belonging to this genus remained stable during the repeated backsloppings and increase of the nutritional and functional properties of the fermented products.

Vogelmann and Hertel (2011) investigated the behaviour of several co-cultures containing Lactobacillus sanfranciscensis and Candida humilis strains, respectively Lactobacillus reuteri, Lactobacillus johnsonii and Issatchenkia orientalis strains in the sourdoughs production. They concluded that the Lactobacillus sanfranciscensis and Candida humilis co-culture was the most suitable for the wheat and rye sourdough production, when the fermentation was carried out at temperatures between $20-30^{\circ} \mathrm{C}$. They recommended that between 5$20 \%$ of the fermented sourdough should be used for the daily backslopping. Also, they demonstrated that Lactobacillus spp. and Issatchenkia orientalis strains can be competitive in a fermentation conducted at $35-40^{\circ} \mathrm{C}$, using as a fermentation substrate wheat flour, rye flour and bran. 
The strains' diversity and their metabolic behaviour depend on the fermentation parameters $(\mathrm{pH}$, time and temperature), factors that define the final characteristics of the sourdough. The study of the $\mathrm{pH}$ influence on the spontaneously fermented liquid wheat sourdough revealed that some differences were observed between the sourdough with a $\mathrm{pH}$ value of 4.0 and the other sourdoughs with a lower $\mathrm{pH}$. Precisely, when the $\mathrm{pH}$ was kept at 4.0 the amounts of lactic acid isomers and ethanol increased and the metabolic activity of Lactobacillus fermentum, L. plantarum, L. paraplantarum and L. pentosus strains was not affected. Lower $\mathrm{pH}$ values led to an accumulation of volatile compounds that enhanced the flavour (Van Kerrebroeck et al., 2016). Other studies stated that a low $\mathrm{pH}$ value can influence the hardness of the bread, so the optimization of the fermentation parameters must be assured in order to obtain a high-quality product (Siepmann et al., 2019).

The parameters for the starter cultures' production when taking under consideration the medium-dependent factors (room temperature, refrigeration, freezing, stability at light and atmospheric oxidation, no heat-associated denaturation) that must be ensured are the viability and the stability during preservation. Nowadays, freezedried products are preferred since they are easy to handle, have an extended storage time and offer reproducible results.

Skim milk powder $(10 \%)$ supplemented with monosodium glutamate $(5 \%)$ was the best combination of cryoprotectants when freeze-drying was applied for the preservation of a consortium of LAB and yeast strains. After one year of storage at room temperature, $87 \%$ of the bacterial cells' viability was recovered (Stefanello et al., 2019). The study conducted by Lu et al. (2017) followed the findings presented above, mentioning that the Streptococcus thermophilus strain was preserved using $116.4 \mathrm{~g} / \mathrm{L}$ skim milk, $77.4 \mathrm{~g} / \mathrm{L}$ sodium glutamate and $79.6 \mathrm{~g} / \mathrm{L}$ glycerol. This medium composition offered a viability of $93.58 \%$ for the Streptococcus thermophilus cells. The best survival rate for the starter culture containing one Lactobacillus rhamnosus strain, that was stored at room temperature, was obtained when the spray drying with a phosphate buffer solution supplemented with lactose or trehalose was used (Broeckx et al., 2017). Spray drying techniques were also used for the microencapsulation of Lactobacillus casei strain with skim milk to maximize the probiotic effect and stability. The stability of the bacterial cells depends not only on the involved strains but also on the preserving technology.

\section{Benefits of sourdough for the bakery products quality and consumer's health}

Cereals contain mainly carbohydrates that are used by the LAB strains to produce metabolites with different biological activities. The endogenous amylases from the flours break down starch into maltodextrins that are hydrolysed to maltose and glucose. The process is presented briefly in Figure 2. Moreover, LAB strains can use unspecific metabolic pathways to produce bioactive peptides and organic acids with antimicrobial properties starting from complex substrates. The sourdough's lactic acid fermentation reduced the allergenicity of wheat and rye flours due to various enzymatic proteolysis reactions. 

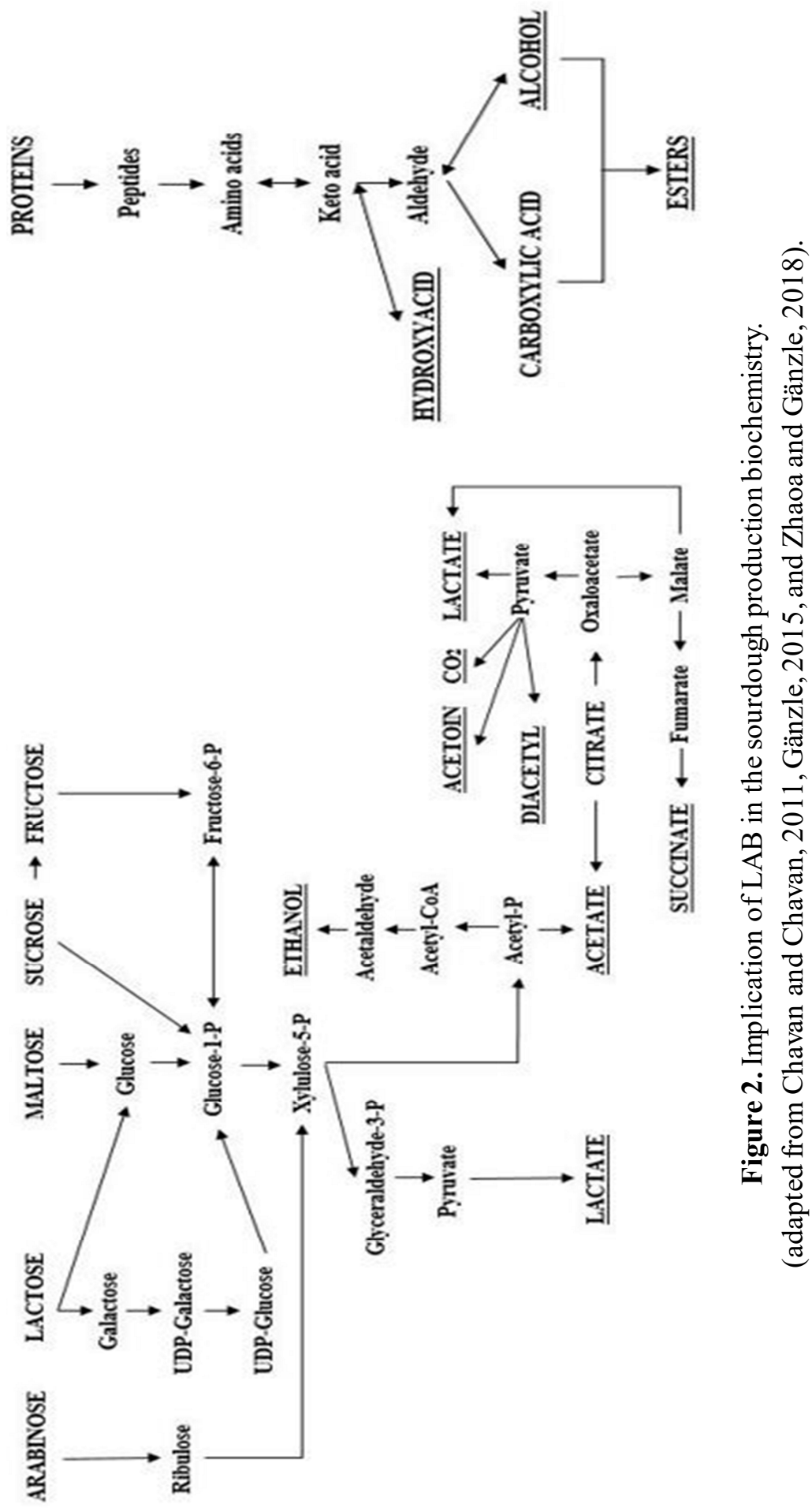
Many LAB strains are able to produce postbiotic compounds like short chain fatty acids (SCFA), especially propionate and butyrate that have positive effects on the patients with irritable bowel disease and inflammatory reactions. Moreover, the fermentation of $\beta$-glucans from oat, barley, wheat, and rye, respectively of raffinose and stachyose from soy flour, chickpea, beans, peas and lentils by selected Lactobacillus spp. strains leads to the production of acetate, propionate and butyrate with therapeutic effect on depression, stress, autism, schizophrenia or anxiety.

\section{Exopolysaccharides production}

Lactic acid bacteria, especially Lactobacillus spp., can produce exopolysaccharides (EPS). Pediococcus spp., Lactobacillus spp., Weissella spp., and Leuconostoc spp. strains are involved in the biosynthesis of extracellular homopolysaccharides whereas Streptococcus spp., Lactococcus spp. and Lactobacillus spp. strains produce heteropolysaccharides (Xu et al., 2019). The concentrations of the synthesized exopolysaccharides could be related to a multitude of factors such as the nutritional composition of the substrates, optimum fermentation conditions, strains and their biochemical properties. Exopolysaccharides can be used as prebiotics, being able to substitute hydrocolloids in gluten-free bread or other foods in order to increase their functionality. Therefore, the EPS produced by LAB strains have antimicrobial and anticarcinogenic effects. They can form complexes with the free radicals and prevent cardiovascular diseases by lowering the cholesterol level. It was demonstrated that the EPS-containing products consumption had a positive impact on the immune system along with a better glycemic response of patients with diabetes. Moreover, the utilization of LAB and/ or yeast strains that produce EPS and polyols to reduce the amount of sugar in bakery products and enhance the textural features is a common practice today. Therefore, mannitol (Lactobacillus sanfranciscensis, Leuconostoc mesenteroides, Leuconostoc citreum), erythritol (Leuconostoc oenos) and xylitol (Candida milleri) producers were tested.

Zhou et al. (2016) demonstrated that the mineral content of the fermentation substrates is an important biotechnological factor for the production of exopolysaccharides. Thus, some Lactobacillus plantarum strains growth on a selenium-enriched fermentation medium led to an increased production of a watersoluble heteropolysaccharide.

The artisanal fermented wheat bran sourdough was a good source for the isolation of two EPS producing LAB strains. One of them belongs to the Lactobacillus spp. genera that produced an EPS with a molecular weight of $5.36 \times 10^{5}$ Da whereas the other one was a Pediococcus pentosaceus strain that synthesizes EPS with a molecular weight of $4.65 \times 10^{5} \mathrm{Da}$ (Abedfar et al., 2018). Weissella confusa OF126 strain demonstrated that it can survive under acidic conditions or together with bile salts for more than 48 hours, at $\mathrm{pH} 7.0$, by cultivation on a modified MRS medium supplemented with $24 \mathrm{~g} / \mathrm{L}$ sucrose and $25 \mathrm{~g} / \mathrm{L}$ yeast extract. The strain produced $3 \mathrm{~g} / \mathrm{L}$ EPS with a molecular weight of $1.1 \times 10^{6} \mathrm{Da}$ (Adesulu-Dahunsi et al., 2018). 
Lactobacillus plantarum KX041 strain produced by cultivation in a MRS-modified medium containing $20 \mathrm{~g} / \mathrm{L}$ soybean peptone and $30 \mathrm{~g} / \mathrm{L}$ lactose, $\mathrm{pH} 6.38$, at $35^{\circ} \mathrm{C}$ for 28 hours, an EPS with antioxidant activity and a molecular weight of $38.67 \mathrm{kDa}$ (Wang et al., 2017).

\section{Antioxidant activity improvement and the reduction of antinutritional factors}

Dietary antioxidants supplementation increases the body defence against oxidative stress. Lactic acid fermentation is one of the most used biotechnological processes that decreases the level of antinutrients in foods, along with washing, soaking, sprouting, dehulling and thermal processing. Udomkun et al. (2019) demonstrated that by mixing maize, sorghum, sesame, soybean cassava, rice or banana flours a significant reduction of phytic acid can be obtained. The authors also demonstrated that cassava and rice flours had lower tannin and phytate contents, fact that makes them good candidates for composite flours, whereas the banana flour had a higher concentration of tannins.

Lactic acid fermentation parameters are important factors that can change the composition of the fermented product and its functionality. The influence of the fermentation time and temperature was analysed for a whole-grain sorghum spontaneously fermented product at $27^{\circ} \mathrm{C}$ for 24 hours, compared to a fermented product obtained at $28^{\circ} \mathrm{C}$ for 48 hours. The increment of the fermentation time determined a decrease of the antioxidants and also a lower concentration of tannins, although the acidity and organic acids levels were higher (Adebo et al., 2018a). The whole grains of sorghum with different concentrations of tannins were studied when a single or mixed starter culture of Lactobacillus fermentum strains was used to start the fermentation. The influence of different fermentation parameters $\left(34^{\circ} \mathrm{C}\right.$ for 24 hours and $28^{\circ} \mathrm{C}$ for 72 hours) on the antinutritional factors and antioxidants was analysed. The study highlighted that the sorghum with a high tannins content had a better antioxidant capacity, an activity related to the gallic acid, quercetin and catechin contents released after the fermentation. Furthermore, the single or the mixed LAB strains used for the undertaken fermentation decreased the tannins level and increased the flavonoids and total phenolic content (Adebo et al., 2018b).

The phytic acid content can be reduced by various endogenous and exogenous enzymes biosynthesized by LAB. Two lactic acid bacteria strains isolated from sorghum, Lactobacillus plantarum W723 and Streptococcus cremoris W722 respectively, released high quantities of extracellular phytases (Ogunremi et al., 2017). The genes responsible for the phytate degradation were taken from Bifidobacterium ssp. and inserted into the Lactobacillus casei genome. The Lactobacillus casei strain was used afterwards for the whole wheat flour sourdough production but unfortunately the reduction of phytate in the sourdough was not significant due to the particle size of the whole wheat flour, the available water content and the reduced viability. Instead, when the fermentation took place in the MRS broth, this modified strain was able to decrease the phytate concentration (García-Mantrana et al., 2016). 
The protein-rich and starch-rich fractions of the dehulled faba bean flour were fermented with one Lactobacillus plantarum strain. The fermentation reduced the trypsin inhibitor activity and the condensed tannins, substances that were concentrated in the protein-rich fraction of the flour (Coda et al., 2015).

It was demonstrated that the thermal treatment could modify the composition of the raw sample. As such, through the lamination $\left(100^{\circ} \mathrm{C}, 11 \mathrm{sec}, 5 \mathrm{rpm}\right)$ and puffing $\left(160^{\circ} \mathrm{C}, 30 \mathrm{sec}\right)$ of the amaranth seeds in order to minimize the level of antinutritional factors, the phytic acid concentration was reduced although no significant changes were noticed in regards to the bioavailability of zinc and calcium. However, a positive effect was obtained concerning the iron composition (Burgos et al., 2018).

Sharma et al. (2018) demonstrated that the foxtail millet soaked for 60 min at 400 MPa and $60^{\circ} \mathrm{C}$ had the lowest concentrations of tannins and phytic acid. Also, an enhanced antioxidant capacity was observed. The authors demonstrated that the bioactive compounds concentration was increased through the foxtail millet germination, while the antinutritional factors content was reduced.

The submerged fermentation of buckwheat flour with selected LAB strains was studied in order to see the influence of a preliminary treatment $\left(90^{\circ} \mathrm{C}, 15 \mathrm{~min}\right.$ followed by sterilization) on the buckwheat nutritional and bioactive compounds. After the fermentation of the raw buckwheat with the Lactobacillus plantarum strain, the level of total phenolic content was $2.16 \mathrm{mg}$ gallic acid equivalent/g dry basis. For the roasted sample, the total phenolic content of $1.21 \mathrm{mg}$ gallic acid equivalent/ g dry basis was determined for the substrate fermented with the Lactobacillus acidophilus strain (Zieliński et al., 2019).

The sourdough from pearl millet, fermented with the Weissella confusa strain that is able to synthesize dextran, was added $(10 \%)$ to the bread made with whole grain pearl millet and wheat flours. Although the total phenolic content of the sourdough bread fermented with Weissella confusa strain was smaller compared to the control, the free phenolics concentration in the sourdough bread was higher (Wang et al., 2019).

The phenolic content of a bread made with wheat flour, hop sourdough and rice bran was substantially improved, as well as the sensorial and technological properties of the fortified product.

Wheat flour from two wheat varieties with different maturity levels was subjected to fermentation with a mixed starter containing Lactobacillus plantarum 98a, Lactobacillus sanfranciscensis BB12 and Lactobacillus brevis 3BHI strains. Then, the fermented products were cooked at $250^{\circ} \mathrm{C}$ for $20 \mathrm{~min}$ or at $210^{\circ} \mathrm{C}$ for $10 \mathrm{~min}$. After the thermal treatments, the highest total polyphenols content $(433.12 \mathrm{mg} / 100$ $\mathrm{g}$ dry base) was assessed for the immature wheat sourdough after a thermal treatment at $250^{\circ} \mathrm{C}$ (Saa et al., 2017).

Chi and Cho (2016) compared the impact of soybean groats fermentation using a Bacillus spp. strain with the samples fermented using a starter culture made of Lactobacillus spp. and Saccharomyces cerevisiae strains. They demonstrated that 
the LAB and yeast consortium was not as effective as the Bacillus spp. single fermentation on the antinutritional factors reduction (trypsin inhibitor, raffinose and stachyose).

\section{Assurance of the biopreservation of bakery products through the use of sourdough}

Some metabolites produced by microorganisms during fermentation could play the role of biopreservatives by being used as sourdough by-products in bread making, as follows:

\section{Acids}

Sourdough bread has an extended shelf-life and a better sensorial quality due to some organic acids (lactic, acetic and propionic), a fact that comes with a delayed microbial contamination, a starch retrogradation process, as well as a higher concentration of free amino acids. It was reported that a new strain of Lactobacillus reuteri isolated from whole wheat sourdough can inhibit the Aspergillus niger growth and the B1, B2, G1 and G2 aflatoxins biosynthesis (Sadeghi et al., 2019). The supplementation of the fermentation medium with specific growth factors can increase the biosynthesis of the targeted metabolites. This idea was highlighted by Schmidt et al. (2017) who demonstrated that the phenyl lactic acid biosynthesis yield was significantly higher when phenylalanine $(1.5 \%)$ was added in the cultivation medium of a Lactobacillus reuteri strain, at $37^{\circ} \mathrm{C}$ for 48 hours.

A $24 \mathrm{~h}$ cell-free supernatant from Lactobacillus plantarum strain had a higher concentration of lactic acid that made it suitable for biopreservation purposes (Russo et al., 2017). Axel et al. (2016) identified numerous antifungal compounds (4-hydroxyphenyl acetic acid, 4-hydroxybenzoic acid, 3-phenyl lactic acid, benzoic acid, salicylic acid, 2-hydroxyisocaproic acid, 2-hydroxydodecanoic acid, $\beta$ hydroxy lauric acid) in the quinoa and rice sourdoughs fermented by Lactobacillus reuteri and Lactobacillus brevis strains at $37^{\circ} \mathrm{C}$ and $30^{\circ} \mathrm{C}$, respectively for 48 hours.

The presence of linoleic and ricinoleic fatty acids in the cultivation medium determined the biosynthesis of different conjugated linoleic acid isomers (CLA) when Lactobacillus spp. or Bifidobacterium spp. strains were involved in the fermentation process (Ogawa et al., 2005). The fatty acids content in the fermented medium was modified when Lactococcus spp. and Leuconostoc mesenteroides ssp. mesenteroides were used in a co-culture. The fermented product had a better functionality due to the antilisterial properties (Borges et al., 2019). Dietary polyunsaturated fatty acids (PUFA) inhibit Staphylococcus spp., Streptococcus spp., Mycobacterium spp., Helicobacter spp., and Bacillus spp. Furthermore, they have a positive impact on the fatty liver and cardiovascular associated diseases. It should be mentioned that the ratio between different PUFAs is a decisive factor that can make the difference between the health-promoting effects and the unwanted side effects. The study conducted by Nakamura et al. (2019) emphasized that the consumption of fatty acids that contain from 4 to 10 carbons is not related 
to the risk of cardiovascular diseases. Instead, the dietary long-chain fatty acids (12-22 carbons) represent a risk factor for cardiovascular disorders.

\section{Peptides and other biopreservatives}

Bacteriocins have antifungal and bactericidal effects on either pathogenic or LAB strains. The incorporation in foods of LAB strains that biosynthesize bacteriocins enhances the antioxidant, anti-inflammatory and hypocholesterolemic properties of the final products. Lactobacillus spp. and Pediococcus spp. strains are used frequently for their bacteriocin-producing capacity. It was reported that garviecin, a class II bacteriocin, produced by the Lactococcus garvieae strain is not affected by heat treatment, lipolytic and amylolytic enzymes. Although the bacteriocin remained active at low $\mathrm{pH}$ values against Gram-positive and Gram-negative bacteria, its activity was affected by proteases (Gao et al., 2015). Staphylococcus aureus and Pseudomonas aeruginosa were inhibited by the Lactococcus spp. extracellular bacteriocins released in the MRS broth. The maximum biosynthesis was noticed at $\mathrm{pH}$ values between 5.0-7.0 and $28^{\circ} \mathrm{C}$ (Barman et al., 2018). Lactobacillus plantarum, Lactobacillus reuteri and Lactobacillus gasseri strains produced small heat-stable bacteriocins in the presence of bile salts that were active under acidic conditions against Listeria monocytogenes and Bacillus cereus (Mohammadi et al., 2018; Lv et al., 2018). Pediococcus acidilactici produced a bacteriocin in MRS broth, after 20 hours of fermentation at $37^{\circ} \mathrm{C}$, which was stable at $\mathrm{pH}$ values ranging from 2.0 to 11.0 and it had an antibacterial effect against Listeria innocua and Streptococcus mutans. The pediocin was inactivated by $\alpha$ amylases and proteases (Ahn et al., 2017). Rizzello et al. (2016) reported that a mixture of pea, lentil and faba bean flours hydrolysed with a commercial protease can increase significantly the shelf-life of wheat bread, up to 14 days, due to the bioactive proteins and peptides.

Experimental design tests were carried out to establish the maximum antilisterial bacteriocin biosynthesis capacity of a Lactobacillus plantarum strain cultivated on a whey based medium. The undertaken study showed that the whey based medium supplementation with soybean extract, tryptone, and $\mathrm{B}_{12}$ vitamin increased the antimicrobial properties when the fermentation took place under agitation $(50 \mathrm{rpm})$ for 48 hours at $30^{\circ} \mathrm{C}$. Lactobacillus salivarius's bacteriocin strongly inhibited Streptococcus spp., Staphylococcus aureus, Enterococcus faecium and Micrococcus luteus at $\mathrm{pH}$ values between 2.0-5.0 and temperatures between 40$80^{\circ} \mathrm{C}$. Salivaricin was produced in the MRS broth at $37^{\circ} \mathrm{C}$ after 20 hours of fermentation. A novel fermentation medium with tryptone, peptone, yeast extract, glucose, ascorbic acid, Tween 80 and salts was used to increase the amount of bacteriocin. The influence of temperature $\left(20^{\circ} \mathrm{C}, 25^{\circ} \mathrm{C}\right.$, and $\left.30^{\circ} \mathrm{C}\right)$ and the $\mathrm{NaCl}$ concentration $(0 \%, 2 \%, 4 \%$, and $6 \%)$ on the biosynthesis of an antilisterial plantaricin was also studied and it was concluded that the bacteriocin activity decreased with the increasing concentration of $\mathrm{NaCl}$ along with the decrease of the incubation temperature. Lactobacillus sakei ssp. sakei strain was able to grow and produce antilisterial bacteriocin at $4^{\circ} \mathrm{C}$ when a medium composed of peptone 
$(1.8 \%)$, beef extract $(1.2 \%)$, yeast extract $(0.6 \%)$, starch $(2 \%)$ and glucose $(0.5 \%)$ was used (Barbosa et al., 2018).

The compounds with properties similar to those of bacteriocins, whose amino acids sequence was not characterized, are recognized in the literature as bacteriocin-like inhibitory substances (BLIS). Pediococcus spp. and Lactobacillus spp. strains isolated from sourdough can produce BLIS with inhibitory activity against Bacillus subtilis making them suitable for bakery products biopreservation. The BLIS synthesized by Lactobacillus spp. strains remained active for months even when different stressors $(\mathrm{pH}$, temperature and ethanol) were applied. Moreover, goat cheese whey was the best cultivation medium for the Lactococcus lactis strain that produces BLIS antibacterial compounds. The positive effects of BLIS can be enhanced if the cultivation parameters for the Lactococcus spp. strain are optimized (Chaves de Lima et al., 2017).

\section{Conclusions and future perspectives}

Even though the sourdough production field was studied in the last decades and the literature offers various scientific data, there is still an increasing interest in this topic for a better understanding of the processes. The sourdough technology innovations are still to be found from now on because there are a lot of valuable but underutilized foods, ingredients and industrial by-products. Making food products that can satisfy the special nutritional requirements involves the diversification of the flours used in the sourdough production, the unconventional ones being brought currently under the attention of specialists for their nutritional and functional properties. Moreover, in the near future, new microorganism strains will be discovered, and their performances will be adapted so to obtain fermented products with improved properties. At the same time, the shelf-life extension using innovative healthy technologies that provide an increased functionality will also be regarded as future concerns. These objectives could be reached only if systematic approaches will be employed by taking into account the technological, nutritional and functional aspects that will lead to a better life quality.

\section{References}

Abedfar, A., Hosseininezhad, M., Sadeghi, A., Raeisi, M., Feizy, J. 2018. Investigation on "spontaneous fermentation" and the productivity of microbial exopolysaccharides by Lactobacillus plantarum and Pediococcus pentosaceus isolated from wheat bran sourdough. LWT-Food Science and Technology, 96, 686-693.

Adebo, O.A., Njobeh, P. B., Adebiyi, J.A., Kayitesi, E. 2018a. Co-influence of fermentation time and temperature on physicochemical properties, bioactive components and microstructure of ting (a Southern African food) from whole grain sorghum. Food Bioscience, 25, 118-127.

Adebo, O.A., Berka Njobeh, P., Kayitesi, E. 2018b. Fermentation by Lactobacillus fermentum strains (singly and in combination) enhances the properties of ting from two whole grain sorghum types. Journal of Cereal Science, 82, 49-56. 
Adesulu-Dahunsi, A.T., Sanni, A.I., Jeyaram, K., Ojediran, J.O., Ogunsakin, A.O., Banwo, K. 2018. Extracellular polysaccharide from Weissella confusa OF126: Production, optimization, and characterization. International Journal of Biological Macromolecules, 111, 514-525.

Ahn, H., Kim, J., Kim, W.J. 2017. Isolation and characterization of bacteriocin-producing Pediococcus acidilactici HW01 from malt and its potential to control beer spoilage lactic acid bacteria. Food Control, 80, 59-66.

Awika, J.M. 2017. Sorghum: Its Unique Nutritional and Health-Promoting Attributes, In: Gluten-Free Ancient Grains. Cereals, Pseudocereals, and Legumes: Sustainable, Nutritious, and Health-Promoting Foods for the 21st Century, Taylor, J. R., Awika, J. M. (Eds.) Woodhead Publishing, pp. 21-54.

Axel, C., Brosnan, B., Zannini, E., Furey, A., Coffey, A., Arendt, E.K. 2016. Antifungal sourdough lactic acid bacteria as biopreservation tool in quinoa and rice bread. International Journal of Food Microbiology, 239, 86-94.

Barbosa, M.S., Jurkiewicz, C., Landgraf, M., Todorov, S.D., Franco, B.D.G.M. 2018. Effect of proteins, glucose and $\mathrm{NaCl}$ on growth, biosynthesis and functionality of bacteriocins of Lactobacillus sakei subsp. sakei $2 \mathrm{a}$ in foods during storage at $4^{\circ} \mathrm{C}$ : Tests in food models. LWT-Food Science and Technology, 95, 167-171.

Barman, S., Ghosh, R., Mandal, N.C. 2018. Production optimization of broad spectrum bacteriocin of three strains of Lactococcus lactis isolated from homemade buttermilk. Annals of Agrarian Science, 16, 286-296.

Borges, D.O., Matsuo, M.M., Bittencourt Bogsan, C. S., da Silva, T.F., Casarotti, S.N., Barretto Penna, A.L. 2019. Leuconostoc mesenteroides subsp. mesenteroides SJRP55 reduces Listeria monocytogenes growth and impacts on fatty acids profile and conjugated linoleic acid content in fermented cream. LWT-Food Science and Technology, 107, 264-271.

Broeckx, G., Dieter Vandenheuvel, D., Henkens, T., Kiekens, S., van den Broek, M.F.L., Lebeer, S., Kiekensa, F. 2017. Enhancing the viability of Lactobacillus rhamnosus GG after spray drying and during storage. International Journal of Pharmaceutics, 534, 35-41.

Burgos, V.E., Binaghi, M.J., Ronayne de Ferrer, P.A., Armada, M. 2018. Effect of precooking on antinutritional factors and mineral bioaccessibility in kiwicha grains. Journal of Cereal Science, 80, 9-15.

Chavan, R.S., Chavan, S.R. 2011. Sourdough Technology-A Traditional Way for Wholesome Foods: A Review. Comprehensive Reviews in Food Science and Food Safety, 10, 171-184.

Chaves de Lima, E.L., Fernandes, J.M., Cardarelli, H.R., 2017. Optimized fermentation of goat cheese whey with Lactococcus lactis for production of antilisterial bacteriocin-like substances. LWT - Food Science and Technology, 84, 710-716.

Chi, C.-H., Cho, S.-J. 2016. Improvement of bioactivity of soybean meal by solid-state fermentation with Bacillus amyloliquefaciens versus Lactobacillus spp. and Saccharomyces cerevisiae. LWT-Food Science and Technology, 68, 619-625.

Coda, R., Melama, L., Rizzello, C.G., Curiel, J.A., Sibakov, J., Holopainen, U., Pulkkinen, M., Sozer, N. 2015. Effect of air classification and fermentation by Lactobacillus plantarum VTT E-133328 on faba bean (Vicia faba L.) flour nutritional properties. International Journal of Food Microbiology, 193, 34-42.

D’Amico, S., Schoenlechner, R. 2017. Amaranth: Its Unique Nutritional and HealthPromoting Attributes, In: Gluten-Free Ancient Grains. Cereals, Pseudocereals, and 
Legumes: Sustainable, Nutritious, and Health-Promoting Foods for the 21st Century, Taylor, J. R., Awika, J. M. (Eds.) Woodhead Publishing, pp. 131-159.

Duodu, K.G., Apea-Bah, F.B. 2017. African Legumes: Their Unique Nutritional and Health-Promoting Attributes, In: Gluten-Free Ancient Grains. Cereals, Pseudocereals, and Legumes: Sustainable, Nutritious, and Health-Promoting Foods for the 21st Century, Taylor, J. ., Awika, J.M. (Eds.) Woodhead Publishing, pp. 223-269.

Gänzle, M.G. 2015. Lactic metabolism revisited: metabolism of lactic acid bacteria in food fermentations and food spoilage. Current Opinion in Food Science, 2, 106-117.

Gao, Y., Li, D., Liu, S., Zhang, L. 2015. Garviecin LG34, a novel bacteriocin produced by Lactococcus garvieae isolated from traditional Chinese fermented cucumber. Food Control, 50, 896-900.

García-Mantrana, I., Yebra, M.J., Haros, M., Monedero, V. 2016. Expression of bifidobacterial phytases in Lactobacillus casei and their application in a food model of whole-grain sourdough bread. International Journal of Food Microbiology, 216, 18-24.

Huys, G., Daniel, H.-M., De Vuyst, L. 2013. Taxonomy and Biodiversity of Sourdough Yeasts and Lactic Acid Bacteria, In: Handbook on Sourdough Biotechnology, Gobbetti, M., Gänzle, M. (Eds.) Springer, pp. 105-154.

Lu, Y., Huang, L., Yang, T., Lv, F., Lu, Z. 2017. Optimization of a cryoprotective medium to increase the viability of freeze-dried Streptococcus thermophilus by response surface methodology. LWT - Food Science and Technology, 80, 92-97.

Lv, X., Miao, L., Ma, H., Bai, F., Lin, Y., Sun, M., Li, J. 2018. Purification, characterization and action mechanism of plantaricin JY22, a novel bacteriocin against Bacillus cereus produced by Lactobacillus plantarum JY22 from golden carp intestine. Food Science and Biotechnology, 27(3), 695-703.

Mohammadi, F., Eshaghi, M., Razavi, S., Sarokhalil, D.D., Talebi, M., Reza Pourshafie, M. 2018. Characterization of bacteriocin production in Lactobacillus spp. Isolated from mother's milk. Microbial Pathogenesis, 118, 242-246.

Nakamura, H., Tsujiguchi, H., Kambayashi, Y., Hara, A., Miyagi, S., Yamada, Y., Nguyen, T.T., Shimizu, Y., Hori, D., Nakamura, H. 2019. Relationship between saturated fatty acid intake and hypertension and oxidative stress. Nutrition, 61, 8-15.

Ogawa, J., Kishino, S., Ando, A., Sugimoto, S., Mihara, K., Shimizu, S. 2005. Production of Conjugated Fatty Acids by Lactic Acid Bacteria. Journal of Bioscience and Bioengineering, 100(4), 355-364.

Ogunremi, O.R., Banwo, K., Sanni, A.I. 2017. Starter-culture to improve the quality of cereal-based fermented foods: trends in selection and application. Current Opinion in Food Science, 13, 38-43.

Papadimitriou, K., Zoumpopoulou, G., Georgalaki, M., Alexandraki, V., Kazou, M., Anastasiou, R., Tsakalidou, E. 2019. Sourdough bread, In: Innovations in Traditional Foods, Galanakis, C. M. (Ed.) Woodhead Publishing, pp. 127-158.

Rizzello, C.G., Coda, R., Gobbetti, M. 2015. Use of sourdough fermentation and nonwheat flours for enhancing nutritional and healthy properties of wheat-based foods, In: Microorganisms and Fermentation of Traditional Foods, Ray, R. C., Montet, D. (Eds.) CRC Press, pp. 433-452.

Rizzello, C.G., Verni, M., Bordignon, S., Gramaglia, V., Gobbetti, M. 2016. Hydrolysate from a mixture of legume flours with antifungal activity as an ingredient for prolonging the shelf-life of wheat bread. Food Microbiology, 64, 72-82. 
Russo, P., Arena, M. P., Fiocco, D., Capozzi, V., Drider, D., Spano, G. 2017. Lactobacillus plantarum with broad antifungal activity: A promising approach to increase safety and shelf-life of cereal-based products. International Journal of Food Microbiology, 247, 48-54.

Saa, D.T., Silvestro, R.D., Dinelli, G., Gianotti, A. 2017. Effect of sourdough fermentation and baking process severity on dietary fibre and phenolic compounds of immature wheat flour bread. LWT - Food Science and Technology, 83, 26-32.

Sadeghi, A., Ebrahimi, M., Mortazavi, S.A., Abedfar, A. 2019. Application of the selected antifungal $\mathrm{LAB}$ isolate as a protective starter culture in pan whole-wheat sourdough bread. Food Control, 95, 298-307.

Schmidt, M., Lynch, K.M., Zannini, E., Arendt, E.K. 2017. Fundamental study on the improvement of the antifungal activity of Lactobacillus reuteri R29 through increased production of phenyllactic acid and reuterin. Food Control, 88, 139-148.

Sharma, N., Goyal, S., Alam, T., Fatma, S., Chaoruangrit, A., Niranjan, K. 2018. Effect of high pressure soaking on water absorption, gelatinization, and biochemical properties of germinated and non-germinated foxtail millet grains. Journal of Cereal Science, 83, 162170.

Siepmann, F.B., Sousa de Almeida, B., Waszczynski, N., Spier, M.R. 2019. Influence of temperature and of starter culture on biochemical characteristics and the aromatic compounds evolution on type II sourdough and wheat bread. LWT - Food Science and Technology, 108, 199-206.

Stefanello, R.F., Harumi Nabeshima, E., Thie Iamanaka, B., Ludwig, A., Martins Fries, L. L., Olivier Bernardi, A., Venturini Copetti, M. 2019. Survival and stability of Lactobacillus fermentum and Wickerhamomyces anomalus strains upon lyophilisation with different cryoprotectant agents. Food Research International, 115, 90-94.

Taylor, J.R.N. 2017. Millets: Their Unique Nutritional and Health-Promoting Attributes, In: Gluten-Free Ancient Grains. Cereals, Pseudocereals, and Legumes: Sustainable, Nutritious, and Health-Promoting Foods for the 21st Century, Taylor, J.R., Awika, J.M. (Eds.) Woodhead Publishing, pp. 55-103.

Udomkun, P., Tirawattanawanich, C., Ilukor, J., Sridonpai, P., Njukwe, E., Nimbona, P., Vanlauwe, B. 2019. Promoting the use of locally produced crops in making cereallegume-based composite flours: An assessment of nutrient, antinutrient, mineral molar ratios, and aflatoxin content. Food Chemistry, 286, 651-658.

Van Kerrebroeck, S., Bastos, F.C.C., Harth, H., De Vuyst, L. 2016. A low pH does not determine the community dynamics of spontaneously developed backslopped liquid wheat sourdoughs but does influence their metabolite kinetics. International Journal of Food Microbiology, 239, 54-64

Vogelmann, S.A., Hertel, C. 2011. Impact of ecological factors on the stability of microbial associations in sourdough fermentation. Food Microbiology, 28, 583-589.

Wang, X., Shao, C., Liu, L., Guo, X., Xu, Y., Lu, X. 2017. Optimization, partial characterization and antioxidant activity of an exopolysaccharide from Lactobacillus plantarum KX041. International Journal of Biological Macromolecules, 103, 1173-1184.

Wang, Y., Compaoré-Sérémé, D., Sawadogo-Lingani, H., Coda, R., Katina, K., Maina, N. 2019. Influence of dextran synthesized in situ on the rheological, technological and nutritional properties of whole grain pearl millet bread. Food Chemistry, 285, 221-230. 
Xu, Y., Cui, Y., Yue, F., Liu, L., Shan, Y., Liu, B., Zhou, Y., Lü, X. 2019. Exopolysaccharides produced by lactic acid bacteria and Bifidobacteria: Structures, physiochemical functions and applications in the food industry. Food Hydrocolloids, 94, 475-499.

Zhaoa, X., Gänzle, M. G. 2018. Genetic and phenotypic analysis of carbohydrate metabolism and transport in Lactobacillus reuteri. International Journal of Food Microbiology, 272, 12-21.

Zhou, K., Zeng, Y., Yang, M., Chen, S., He, L., Ao, X., Zou, L., Liu, S. 2016. Production, purification and structural study of an exopolysaccharide from Lactobacillus plantarum BC-25. Carbohydrate Polymers, 144, 205-214.

Zieliński, H., Szawara-Nowak, D., Bączek, N., Wronkowska, M. 2019. Effect of liquidstate fermentation on the antioxidant and functional properties of raw and roasted buckwheat flours. Food Chemistry, 271, 291-297. 